\title{
ASSESSMENT OF MICROSTRUCTURE CHANGES IN HEAT AFFECTED ZONE OF CARBON STEEL WELDS BY PHASED ARRAY PROBES
}

\author{
1,2Tomáš ZAVADIL, ${ }^{2}$ Petr ŽBÁNEK, ${ }^{3}$ Marie MOŘKOVSKÁ \\ ${ }^{1}$ Czech Technical University in Prague, Faculty of Nuclear Sciences and Physical Engineering, Prague, \\ Czech Republic, EU, zavadilt@atg.cz \\ ${ }^{2} A T G$ - Advanced Technology Group s.r.o., Prague, Czech Republic, EU, zbanek@atg.cz \\ ${ }^{3}$ VSB - Technical University of Ostrava, Ostrava, Czech Republic, EU, mar.morkovska@gmail.com \\ https://doi.org/10.37904/metal.2019.868
}

\begin{abstract}
Welding is one of the so-called special processes that require verification to ensure correct execution in sufficient quality. Low-quality weld is not satisfying the requirements for in-service operation, either due to presence of defects (e.g. cracks, lack of fusion, porosity), or due to undesirable microstructure changes in heat-affected zone, that causes degradation of the weld joint. Welds are the main topic of NDT that searches for defects. The main method for detection of internal defects is the ultrasonic testing, that recently saw many new applications. This article shows how to use Phased Array probes to detect microstructure changes due to failure to follow the welding procedure. It was experimentally confirmed that the technique is able to identify microstructure changes in heat-affected zone created by change of welding parameters or by poor restart. The technique may be in principle performed in parallel with ultrasonic testing for defects, so it is possible to be used one instrument to perform complex assessment of weld joint quality.
\end{abstract}

Keywords: Phased array, ultrasonic testing, welding, structural changes

\section{INTRODUCTION}

Welding is currently the main permanent joining technology of metallic parts used widely in all industrial sectors. Satisfactory weld is defined by its ability to suit its designed purpose, i.e. withstand operational loading in given operating conditions. To ensure that the welding process may achieve (in principle) its desired results all structural welds shall follow the Welding Procedure Specification (WPS). WPS is a procedure that was qualified by destructive and nondestructive means to satisfy the original requirements, especially for the yield and ultimate strength. If such procedure is followed thoroughly no systematic errors should occur. Nonsystematic errors may still occur due to e.g. human factor. That may include creation of defects as well as unintended change of microstructure or stress and strain conditions due to induced heat. This article uses a technique of measurement of the longitudinal to transversal ultrasonic waves velocity ratio (further "L/T ratio") introduced by the main author in his article concerning detection of microstructure changes due to creep [1]. It is assumed that $L / T$ ratio should react on microstructure changes on weldments. Such changes can be either through continuous change of welding parameters, by wrong parameters set-up and by (unintentional) restarts (during which the welded volume is affected for prolonged time to the arc). This article aims to verify the ability of the $L / T$ ratio measured by phased array probes to detect fine changes in the heat-affected zone via change of welding parameters as well as by restarts.

\section{PRINCIPLE OF MEASUREMENT}

According to Schneder and Goebbels [2] ultrasonic waves' velocities for generally anisotropic material are function of density, strain in the given axis, Lamé's constants, and Murnaghan's constants. Assuming the tested volume of the material has isotropic behavior, equations for longitudinal $\left(c_{L}\right)$ and transversal $\left(c_{T}\right)$ ultrasonic waves' velocity may be then determined more simply as the following: 
$c_{L}=\sqrt{\frac{E}{\rho} \frac{1-v}{(1+v)(1-2 v)}}$ and $c_{T}=\sqrt{\frac{G}{\rho}}=\sqrt{\frac{E}{\rho} \frac{1}{2(1+v)}}$

where $E$ and $G$ are commonly referred as Young and Shear modulus, $\rho$ is density and $v$ is the Poisson's ratio. In anisotropic scenario the velocities are also affected by anisotropy in elastic properties and inhomogeneous localization of plastic strain, such as slip bands, creation of point defects and yield vertex which is responsible for degradation of elastic modulus, as described by [3-6]. Velocity changes due to changes in elastic properties are generally within units of a percentage [7]. In order to determine each of the velocities with sufficiently high precision, one needs to measure precisely the path which the wave is propagating as well as time of flight (TOF). Modern devices can measure the time with precision of $0.0001 \mathrm{~ms}$, but precise information on path length may not be available on field. Putting velocities into a ratio allows transforming the problem to a singlevariable equation (only variable is the Poisson's ratio) with monotone-increasing features [1]. If path of both wave types is the same, path is not further needed in the calculation and may be substituted by measurement of TOF of each of the wave types:

$\frac{c_{L}}{c_{T}}=\frac{s}{t_{L}} \frac{t_{T}}{s}=\frac{t_{T}}{t_{L}}=\sqrt{\frac{E}{\rho} \frac{1-v}{(1+v)(1-2 v)}} \sqrt{\frac{\rho}{G}}=\sqrt{\frac{2(1-v)}{1-2 v}}=f(v)$

This can help determining current stress-strain conditions as observed by Kumar et al. [8]. Since Young $(E)$ and Shear $(G)$ modulus tend to vary in the same direction in metal, the Poisson's ratio is dependent on how much each of moduli is affected. The higher the Poisson's ratio the less volume change during deformation. In order to assess changes of the material, trend of L/T ratio should be measured alongside the weld bead and include the heat-affected zone (HAZ). Presence weld bead doesn't allow use of straight-beam probes, so angle-beam probes shall be used in through-transmission mode ( 2 probes - transmitter and receiver are used) with beam propagating along $\mathrm{V}$-path through the weld. Because different wave types propagating under the same angle cannot be generated by one probe, a pair of probes (for longitudinal and for transversal waves) need to be used - i.e. measurement would require 4 probes in two pairs, where each pair $(L+T)$ needs to be placed on the same spot on its side of the weld in order to assess the $L / T$ ratio. To avoid such problematic setup, it is possible to use phased array (PA) probes instead. PA probes are a group of transducers in a matrix where each transducer can be controlled independently. PA probes use the Huygens principle to generate macroscopic wave propagating in desired direction and they are able to generate a wide range of angles. Desired type of wave ( $\mathrm{L}$ - longitudinal, $\mathrm{T}$ - transversal) may be generated through wave transform on the interface between the plexi wedge and the tested material. The same applies for the angle of propagation in the material $\beta$ as described by the Snell's law:

$\sin \beta_{L}=\sin a_{1 L} \cdot \frac{c_{L(\text { wedge })}}{c_{L(\text { material })}}$ and $\sin \beta_{T}=\sin a_{2 L} \cdot \frac{c_{L(\text { wedge })}}{c_{T(\text { material })}}$

Because the paths of propagation need to be the same, the angle of propagation of both types of waves needs to be also the same, therefore $\beta_{L}=\beta_{T}=\beta$. The same incident point is achieved via excitation of a specific set of transducers for each type of wave and proper timing of the wave generation. Principle of creation of longitudinal and transversal waves propagating along the same path is in Figure 1.

The same applies for receiving of the signal, but in the inverted order. In such case the effective part of the beam path (propagating through the tested material) is exactly the same for both types of waves. Differences of the path in wedges may be calculated as demonstrated in Figure 2, or more simply assessed experimentally and compensated by adding a "wedge factor" to the result assessed via Eq. (3).

Previous experiments demonstrated, that $\mathrm{L} / \mathrm{T}$ ratio may be measured by conventional straight-beam UT probes. For P265GH it was estimated as $1.817 \pm 0.012$ depending on the heat treatment [1]. This setup cannot 
be used for testing of welds due to presence of the weld bead. Measurement by two straight-beam UT probes is also more prone to errors due to possibly slightly unequal sound paths $(\sigma \sim 0.5 \%)$.

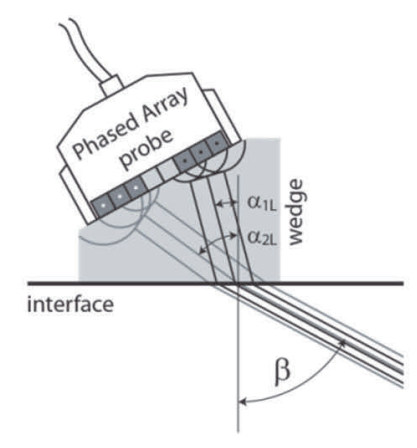

Figure 1 Principle of creation of longitudinal and transversal waves propagating along the same effective path

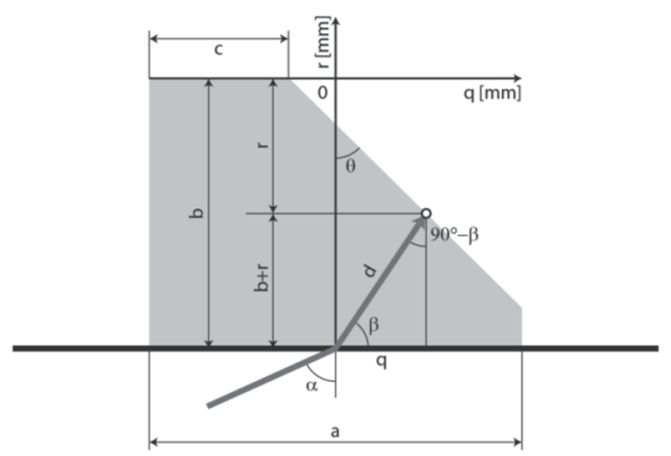

Figure 2 Calculation of the path difference inside a plexi wedge

\section{EXPERIMENTAL SETUP}

The experiment focuses on detection of microstructure changes caused by welding of carbon steel. Sheets of $\mathrm{C} 45+\mathrm{N}$ and $54 \mathrm{SiCr} 6$ steel with thickness $t=15 \mathrm{~mm}$ were utilized for this experiment. The sheet in as-delivered condition was mapped for L/T ratio as a part of the experiment in article [9]. Totally 4 weld joints with weld length $l=320 \mathrm{~mm}$ were created. Each joint had two areas with length $l_{I}=240 \mathrm{~mm}$ and $l_{I I}=80 \mathrm{~mm}$. Area I of each weld was the main measurement area and should have been welded without restart (see Figure 3 on the left). Area II simulated intentional restart (in all beads) and change of welding parameters. Welding was performed by MAG at the Czech Technical University by a qualified operator.
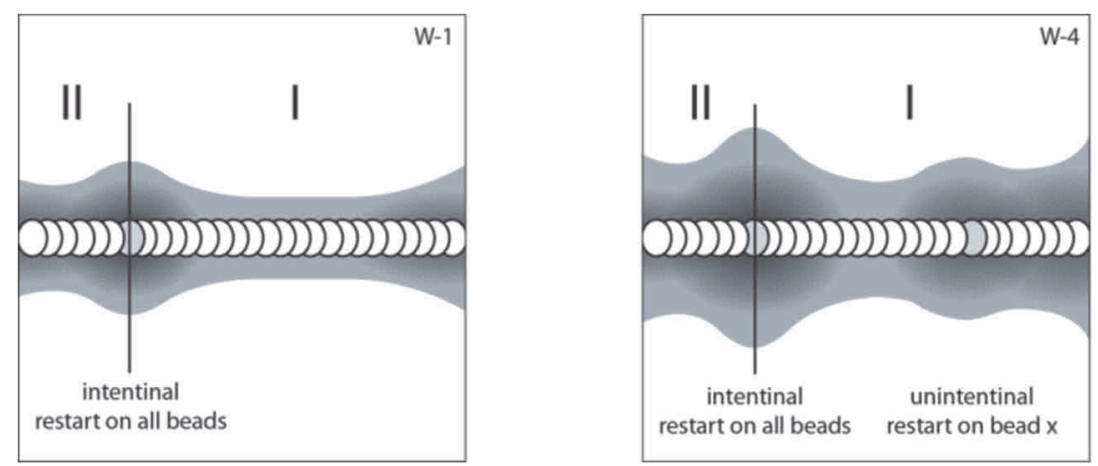

Figure 3 Expected profile of heat-affected zone with standard welding parameters and intentional and increased welding parameters with additional, unintentional (simulated) restart

Weld 1 was welded acc. to qualified Welding Procedure Specification. Welds 2 to 4 had decreased or increased current I (see Table 1). On welds 3 and 4 operator simulated unintentional restart on random places in area I and on each spot only on one bead, including subsurface beads (see Figure 3 on the right).

Calibrated UT instrument Sonatest VEO+ with two 32-transducer phased array probes Sonatest-T1-PE5.0M32E0.8P was used for measurement of TOF. Probes were attached on manipulator MagMan from company Phoenix ISL with one-axis encoder AE-ENCWP (32.8 tics $/ \mathrm{mm})$ with $1 \mathrm{~mm}$ step recording. Probes were placed in the distance of $120 \mathrm{~mm}$. Recorded data were analysed in UT Studio+ software from Sonatest Ltd. Wedge factor was measured by two conventional probes as a mean value of 10 measurements on asdelivered steel and estimated to 1.845 . 
Table 1 Welding parameters of the samples to be tested on areas I and II. Weld 1 was welded acc. to WPS.

\begin{tabular}{|c|c|c|c|c|c|c|c|c|c|c|c|c|c|c|c|c|}
\hline \multirow{3}{*}{$\begin{array}{c}\text { Bead } \\
1-4 \\
\text { Weld 1 }\end{array}$} & \multicolumn{8}{|c|}{ Area I $(I=240 \mathrm{~mm})$} & \multicolumn{8}{|c|}{ Area II $(I=80 \mathrm{~mm})$} \\
\hline & \multicolumn{4}{|c|}{ I [A] } & \multicolumn{4}{|c|}{$\mathbf{U}[\mathbf{V}]$} & \multicolumn{4}{|c|}{ I [A] } & \multicolumn{4}{|c|}{$\mathbf{U}[\mathbf{V}]$} \\
\hline & 145 & 158 & 164 & 164 & 18.9 & 20.1 & 20.7 & 20.7 & 145 & 158 & 164 & 164 & 18.9 & 20.1 & 20.7 & 20.7 \\
\hline Weld 2 & 145 & 125 & 131 & 131 & 18.9 & 17.7 & 17.8 & 17.8 & 145 & 158 & 164 & 164 & 18.9 & 20.1 & 20.7 & 20.7 \\
\hline Weld 3 & 145 & 158 & 164 & 164 & 18.9 & 20.1 & 20.7 & 20.7 & 145 & 190 & 197 & 197 & 18.9 & 23.1 & 23.7 & 23.7 \\
\hline Weld 4 & 145 & 190 & 197 & 197 & 18.9 & 23.1 & 23.7 & 23.7 & 145 & 230 & 230 & 245 & 18.9 & 28.3 & 28.3 & 29.5 \\
\hline
\end{tabular}

\section{RESULTS}

$\mathrm{L} / \mathrm{T}$ ratio dropped from 1.845 before welding to $1.820-1.825$ in the center of the weld on all samples. Majority of samples shown elevated values on edges, probably caused by 3 -axis deformation. The central parts that are not affected by change of welding parameters (e.g. restarts) have plain deformation.

Weld $\mathrm{W}-1$ from $\mathrm{C} 45+\mathrm{N}$ was welded acc. to WPS on both areas. The weld had one (intentional) visible restart along the axis, the weld bead surface was well pronounced. Spattering was not observed (see Figure 4).

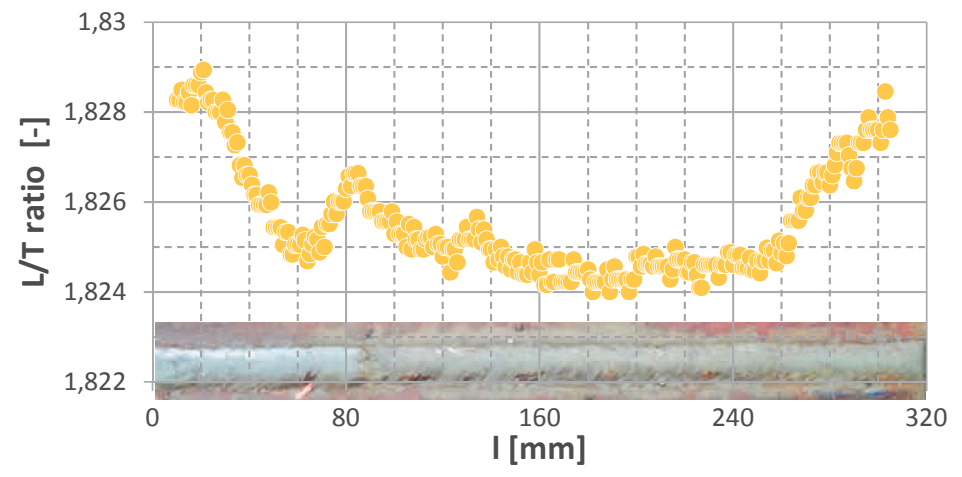

Figure $4 \mathrm{~L} / \mathrm{T}$ ratio alongside the weld axis. Observable restart on I $=80 \mathrm{~mm}$. Change of L/T ratio on restart position of $\mathrm{I}=80 \mathrm{~mm}$ as well as on position $\mathrm{I}=135 \mathrm{~mm}$

Weld W-2 from 54SiCr6 was welded with lowered welding parameters in area I and acc. to WPS in area II. The weld had intentional visible restart, the bead surface was well pronounced (see Figure 5). Spattering was not observed.

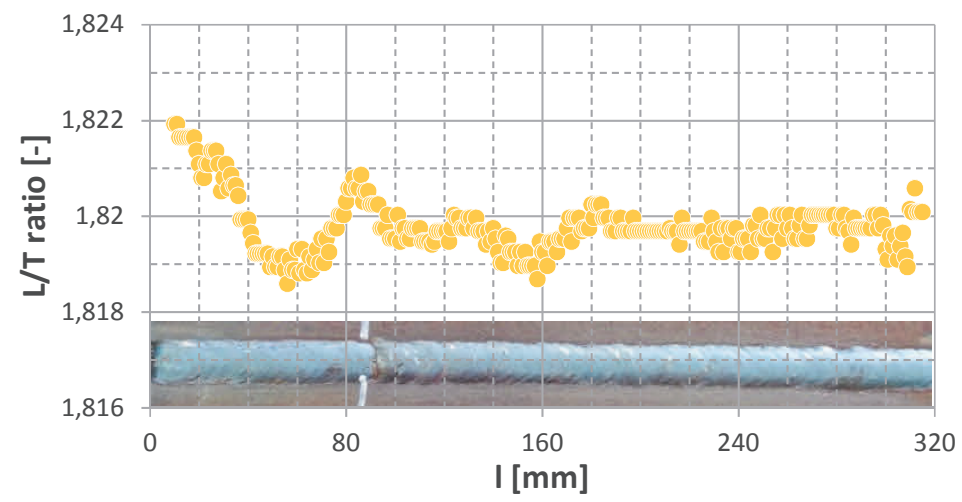

Figure $5 \mathrm{~L} / \mathrm{T}$ ratio alongside the weld axis. Observable restart on I $=80 \mathrm{~mm}$. Observable change of $\mathrm{L} / \mathrm{T}$ ratio on restart position of $\mathrm{I}=80 \mathrm{~mm}$ as well as on position $\mathrm{I}=160 \mathrm{~mm}$ 
Weld W-3 from C45+N was welded acc. to WPS on area I and with increased welding parameters in area II. The weld had one (intentional) and two simulated unintentional visible restarts along the weld axis, the weld bead in the area II was not pronounced well, no spatter was observed on the surface (Figure 6).

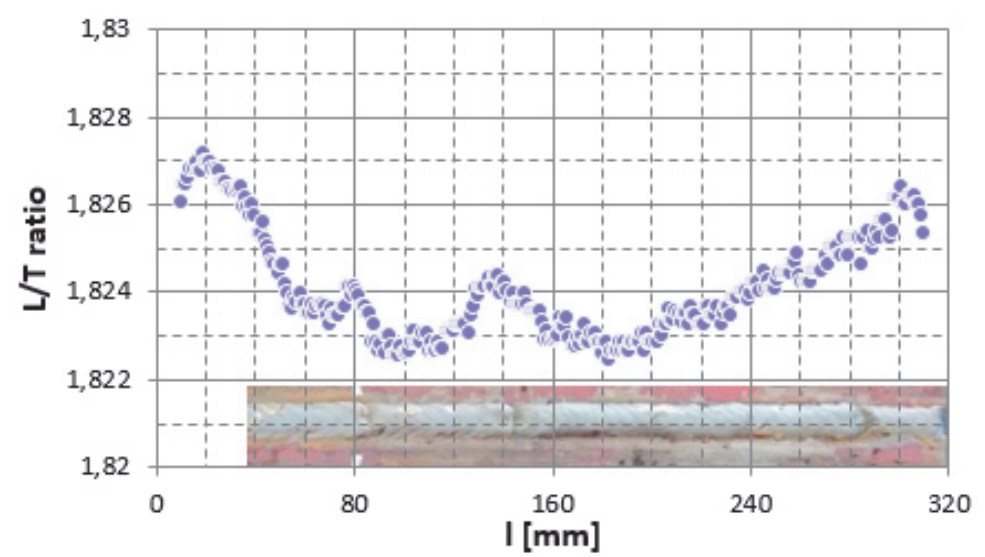

Figure $6 \mathrm{~L} / \mathrm{T}$ ratio alongside the weld axis. Observable restart on I $=70 \mathrm{~mm}, \mathrm{I}=120 \mathrm{~mm}$ and I $=280 \mathrm{~mm}$. Observable change of $\mathrm{L} / \mathrm{T}$ ratio on restart position of $\mathrm{I}=70 \mathrm{~mm}$ as well as on position $\mathrm{I}=120 \mathrm{~mm}$.

Weld W-4 from $\mathrm{C} 45+\mathrm{N}$ steel was welded with increased welding parameters in both areas. The weld had one (intentional) and one more unintentional visible restarts along the weld axis, the weld bead in the area II was not pronounced well, spatter was clearly observed on the surface - see Figure 7.

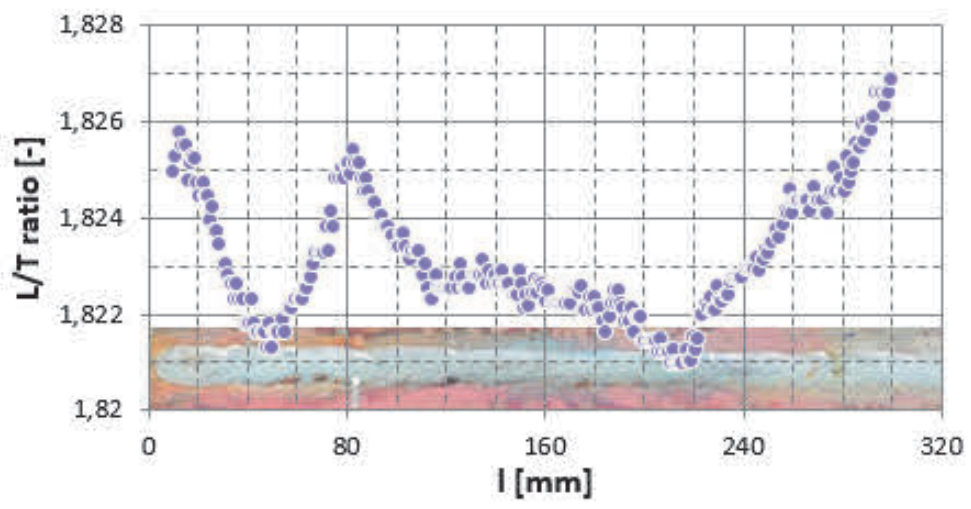

Figure $7 \mathrm{~L} / \mathrm{T}$ ratio alongside the weld axis. Observable restart on I $=80 \mathrm{~mm}$ and I $=240 \mathrm{~mm}$. Observable change of $L / T$ ratio on restart position of $\mathrm{I}=80 \mathrm{~mm}$ as well as on position I $=220 \mathrm{~mm}$ and I $=280 \mathrm{~mm}$.

\section{DISCUSSION}

Testing by $L / T$ ratio confirmed the original expectation based on article [9] that PA probes were able to achieve very low level of uncertainty. Measurements on welded areas without weld restart were equivalent to standard deviation $\sigma$ on parent material before welding (i.e. below 0.001). Mean L/T values on areas I were decreasing with increased welding parameters by approximately 0.002 . Change of $L / T$ ratio due to change of welding parameters was therefore on the edge of measurable level. In order to use such approach specifically for detection of change of welding parameters, additional analysis would be necessary.

$\mathrm{L} / \mathrm{T}$ ratio trend generally followed the same pattern on all samples, elevated at the edges (probably due to 3axis deformation) and keep flat in remaining areas without restarts (plain deformation). L/T ratio in areas with visible restarts had obvious wave pattern visible with elevated values followed by lower values in the direction 
of welding. It is assumed that such behavior is caused by effect of the local deformation field created due to restart. Less pronounced pattern was observed also in areas of simulated unintentional restarts. The welds were performed with 4 beads. On boundary between areas I and II the restart was performed on all beads at the same place, whereas the simulated unintended restarts were performed always only on one bead, as visible in Figures 6 and 7. Some areas had a wave pattern without visible restart - these were most likely restarts on subsurface beads. On weld 4 the area of unintentional restart was more pronounced than the intentional one. It is assumed that the welder mixed up the positions for the intentional and unintentional restarts.

Poor (or unintentional) restarts are common problem of welding process. Each restart is a place with higher probability of presence of defects. Some of them may not be detectable by standard UT setup due to unfavorable orientation of possible defects. Therefore performing the L/T ratio measurement during classical Phased Array inspection (theoretically by the same set of probes, if software would be adjusted to collect both information at the same time) may provide information on suspected areas similarly as the drop of back-wall echo does in conventional A-scan [10].

\section{CONCLUSION}

The article proposes a technique of measurement of longitudinal to transversal ultrasonic waves' velocity ratio which was recently developed by main author to be used for detection of non-satisfactory welds. It was demonstrated that the $L / T$ ratio measurement is able to detect areas of intentional as well as unintentional restarts. These places are more prone for presence of defects. The measurement standard deviation was well controlled for welded steel (similar to as-delivered parent material). The measurement also found detectable change of the L/T ratio due to change of welding parameters. However these changes are close to the edge of detectability compared to the level of uncertainty. In order to use such approach for detection of welding parameters' change, additional measurements are necessary to be performed in future research.

\section{REFERENCES}

[1] ZAVADIL, T. Detection of Creep Degradation on Collapsed Membrane Wall from P265GH Pressure Purpose Steel by Ultrasonic Testing. In ASME 2018 Pressure Vessels and Piping Conference. Prague: ASME, 2018, p. 6.

[2] SCHNEDER, R. and GOEBBELS, K. Zertorungsfreie Bestimmung von Eigenspannungen mit linear polarisierten Ultraschallwellen. VDI Berichte. 1982. no. 439, pp. 189-201.

[3] ELDEVIK, S., OLSEN, O. and LUNDE, P. Sound velocity change owing to the acousto-elastic/plastic effect in steel measured using Acoustic Resonance Technology (ART). In Scandinavian Symposium on Physical Acoustics. Geilo: NTNU, 2012. pp. 12-17.

[4] KOBAYASHI, M. Acoustoelastic Theory for Plastically Deformed Solids. JSME International Journal. 1990. vol. 33, no. 3, pp. 310-318.

[5] KOBAYASHI, M. Ultrasonic Nondestructive Evaluation of Microstructural Changes of Solid Materials Under Plastic Deformation - Part I. Theory. International Journal of Plasticity. 1998. vol. 14, no. 6, pp. 511-522.

[6] KOBAYASHI, M. Analysis of deformation localization based on proposed theory of ultrasonic wave velocity propagating in plastically deformed solids. International Journal of Plasticity. 2010. vol. 26, pp. 107-125.

[7] OBRAZ, V. Zkoušení materiálu ultrazvukem. 1st.ed. Prague: SNTL, 1989. p. 460.

[8] KUMAR, A., JAYAKUMAR, T., RAJ, B. and RAY, K.K. Correlation between ultrasonic shear wave velocity and Poisson's ratio for isotropic solid materials. Acta Materialia. 2003. vol. 51, pp 2417-2426.

[9] ZAVADIL, T., ŽBÁNEK, P. and Mořkovská, M. Options for detection of thermally-induced structural changes of structural steel by Phased Array probes. In NDE for Safety 2018. Prague: ČNDT, 2018. pp. 339-350.

[10] MARKS, P.T. ASNT PTP Handbook. Ultrasonic Testing Classroom Training Handbook. 3rd ed. Columbus: ASNT, 2011. p. 216. 